\title{
Intelligent irrigation in grapevines: a way to obtain different wine characteristics
}

\author{
Flavio Capraro*, Carlos Schugurensky*, Facundo Vita**, Santiago Tosetti*, Andres Lage*, Daniel Patiño* \\ * Instituto de Automática (INAUT). Univesidad Nacional de San Juan, San Juan, Argentina \\ (e-mail: \{fcapraro, carlosu, stosetti, alage, dpatino\}@inaut.unsj.edu.ar). \\ ** Estación Experimental San Juan, Instituto Nacional de Tecnología Agropecuaria (INTA), San Juan, Argentina \\ (e-mail: fvita@sanjuan.inta.gov.ar).
}

\begin{abstract}
This work presents the field implementation of an intelligent irrigation controller, applied to grapevine crops. The proposed irrigation system includes the moisture measurements and the development of an intelligent control system, in order to maintain the moisture level around a set value. Moisture reference value for different irrigation treatments, such as water stress or field capacity, is decided by the user according to the desired enological grape quality. This technology is an appropriate tool for crops managing and, in addition helps to overcome difficulties imposed by a growing water demand and to reduce extraction costs.
\end{abstract}

\section{INTRODUCTION}

The production of wine grapes around the world is usually highly dependent on the irrigation quality and the Argentinean viticulture is not foreign to this problem, especially in San Juan, where the weather is characterized by an atmosphere with high evaporative demand and a poor level of rains (desert and semi-desert climates). From this dependence on the irrigation, together with the lack of water resources, arise the need of developing a new viticulture based on the constant improvement of the efficiency in the use of water. In order to face these needs, this work proposes a close-loop irrigation controller that allows maintaining the moisture level in the roots zone around a set value minimizing variations.

In this work, the implementation of an intelligent irrigation control applied to grapevine (Vitis vinifera cv Malbec), is presented. The desired moisture level (irrigation strategies) in each homogeneous sector is decided by an expert and depends on the grape's final quality at the vintage and the desired wine quality. The introduction of intelligent irrigation control in grapevine crops allows to producers to obtain grapes with different productive and qualitative characteristics, and therefore the possibility of producing high enological quality wines (Coggan, 2002).

A number of investigations show that the use of different irrigation strategies results in a substantial improvement on the quality of musts and wines (McCarthy, 1997; Peterlunger et al., 2000). In addition, it is clear that there exists an important influence of the water regime on the organoleptic characteristics of the wine (Bravdo et al., 1985; Goodwin and Macrae, 1990). The wine quality is directly associated to grape characteristics, such as size of the berry, sugar accumulation, total acidity, colouring intensity, total pigments and concentration of polyphenoles, tannins, and anthocyanins. (Peterlunger et al., 2000). The use of water deficit techniques is a valid option to improve wine characteristics (Matthews et al., 1987; Nadal et al., 1995).

However, the fact of maintain the moisture level at a constant value is a very hard task for the traditional or timed irrigation methods. A possible solution to this problem is to use intelligent irrigation control (Capraro et al., 2006, 2007). The proposed controller allows controlling the irrigation schedule in an automatic way, and therefore, to maintain the moisture level of each homogeneous zone close to different reference values. In this sense, the present paper presents the results of applying two different irrigation treatments from the postveraison and the posterior evaluation of the enological characteristics of the wines obtained from each treatment.

\section{AGRICULTURAL IRRIGATION}

\subsection{Irrigation of agricultural soils.}

Agricultural irrigation programming is a set of technical procedures that allows deciding when and how much to irrigate. Some authors (Pizzarro, 1996; Lopez et. al., 1997), distinguish, at least, three technological alternatives to control the irrigation sequence. These methods are mainly based on measurement of (i) environmental variables, such as temperature, relative humidity, pressure, solar radiation, wind direction and velocity; (ii) plant variables or phytomonitoring, such as crop transpiration, sap flow, or fruit and stem size; and (iii) soil variables, such as temperature, moisture or conductivity.

In the present work, only the volumetric moisture measurement acquired by a capacitive sensor, housed in the root system area, will be used. The main advantage of this approach is that only one sensor per agronomicaly homogeneous parcel (AHP) is needed, where a AHP is a bounded area of land in which soil features, crop and geography must be equal (Coggan, 2002). This method 
allows also making direct and continuous measurements of soil moisture, resulting in an adequate moisture control (Capraro et al., 2006), fact that will be shown in section 4.

\subsection{Agricultural irrigation control.}

Independently from the irrigation method used, four techniques for controlling irrigation sequence can be distinguished. (i) Manual irrigation is perhaps, the most widespread. A man controls the system by opening or closing water circulation and fixing irrigation periods based on his own experience, given a specific crop and soil. (ii) Timed or scheduled irrigation is another technique usually used; a set of timed valves determine period and frequency of preprogrammed irrigation cycles. The same open-close sequence is applied over time, following the program set by an experienced human operator. This is an open-loop control technique, so the system is not able to change its strategy when disturbances or changes in crop's water requirements appear. For example, a sunny day will be the same as a rainy day for this system and irrigation schedule will be accomplished in the same way.

With the addition of moisture sensors, (iii) automatic irrigation appears on stage. In this closed-loop approach, the system has an internal algorithm that implements an irrigation policy and acts based on the information regarding to the soil moisture, gathered by the sensors. For example, in case of rain, sensors can detect the change in soil moisture making the controller to decide that is not necessary to irrigate. In general, the controller decides when to start and how long to irrigate, in order to bring the moisture up to the desired value and then to keep it between specified tolerances. It is usual that some characteristics related to the behavior of the soil in presence of humidity change trough the time. In this case, if the control algorithm keeps its irrigation policy fixed, irrigation periods and cycles will be wrong. In order to address this problem the (iv) intelligent irrigation approach appears (Capraro et al., 2007). This novel control technique measures the error between the steady-state moisture value and the desired moisture value. If this error exceeds some given tolerances, then the control system modifies those parameters related to the calculation of the irrigation periods, so the steady state error can be reduced in future irrigation periods. Continuous measurement and adjustment of errors and parameters respectively, cause the system to improve its behavior through the time.

\subsection{Application of intelligent irrigation on vineyards.}

Present-day trends in viticulture face the need of obtaining differentiated products; for this reason, in order to improve the competitiveness of the business, it is necessary to obtain a variety of wines, so the top line quality segment can be satisfied. However, this high quality wines must not be a product of chemical manipulations. In this sense, the trend in the New World wine producer countries is summarized in the expression the best wines are made in the vines.

Several practices are applied in order to obtain grapefruits with different productive and qualitative characteristics.
Among these, irrigation management is one of the most important tools for modifying wine final quality, and an intelligent irrigation control system plays an important role to this end. The intelligent irrigation controller can keep constant the soil humidity around a set reference value (Hr) for each AHP; this value should be chosen by an expert based on the irrigation treatment needed to obtain certain grape quality. So, by using the strictly necessary amount of water, it should be possible to plan the production of winegrapes of different enological quality.

\subsection{Water management and treatments.}

The water is a fundamental factor for the vegetative development of the vine. An interesting treatment is to supply to the crop less water than the required to restore the water lost by evapotranspiration (ET). This irrigation strategy is known as water deficit causing a state of water stress in the plant. This fact affects the dry mater production and the vegetative growth, what helps to improve light exposition of bunches (Dry and Loveys, 1998; Dry et al., 2001). This work presents the application of two different irrigation treatments, applied along the period from post-veraison to harvest (December $15^{\text {th }}, 2005$ to February $20^{\text {th }}, 2006$ ): (i) the Reference Treatment ( $\mathrm{Tr}$ ), in which the supplied water is enough to maintain the moisture around the field capacity $(\mathrm{Hr}=35 \%$ ), and (ii) Water Restriction Treatment (Twr) that is based on the Regulated Deficit Irrigation (RDI), which implies that the plant is under a moderated water stress $(\mathrm{Hr}=25 \%)$. Characteristics of the wines will be later analyzed.

\section{METHODS AND MATERIALS}

\subsection{Study of the agricultural soil.}

The first step to implement an irrigation control system is to determine the size and quantity of AHPs present in the land in question. After a preliminary study, realized over 4.7ha, located in San Juan, Argentina, three different soils were detected. However, the land was divided in four AHPs: parcels A and C both with a sandy-loam soil; parcel B with a loamy-sand soil; and parcel D with a sandy-clay-loam soil, Fig. 1 presents a schematic map of the area; including location of the control room, water reservoir, humidity sensors and network.

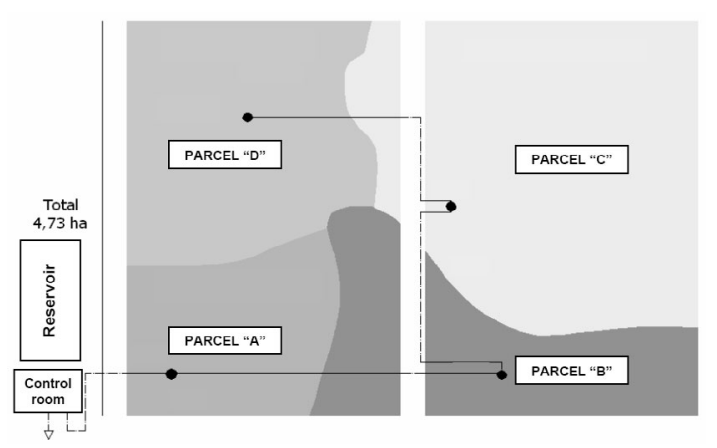

Fig. 1: Distribution of AHPs and moisture sensors.

In particular the analysis will be concentrated on the parcels $\mathrm{A}$ and $\mathrm{C}$, due to the fact that these parcels have identical 
characteristics. In parcel A the Twr will be applied, while in parcel $\mathrm{C}$ will be Tr. Parcels B and D will be subject to water deficit in order to evaluate the irrigation controller, but none grapes quality analysis will be performed.

\subsection{Irrigation equipment and electronic control system.}

Once the AHPs are defined, the next step is to install the pressurized local dripping irrigation system. Drippers of 1.5 $\mathrm{l} / \mathrm{h}$ were used, distributed every $0.8 \mathrm{~m}$ along the irrigation hose. Water provision comes from a reservoir, located close to the control room; this reservoir is filled up by a high caudal pump with water coming from subsoil. The water is taken from the reservoir by a low caudal pump and then passed through a sand filter. These components form the head of the irrigation system and are illustrated in Fig. 2. Each AHP represents an irrigation unit, so each of them has a hydraulic valve that is independently controlled directly from the electronic control system, meaning that each AHP has its own irrigation schedule.
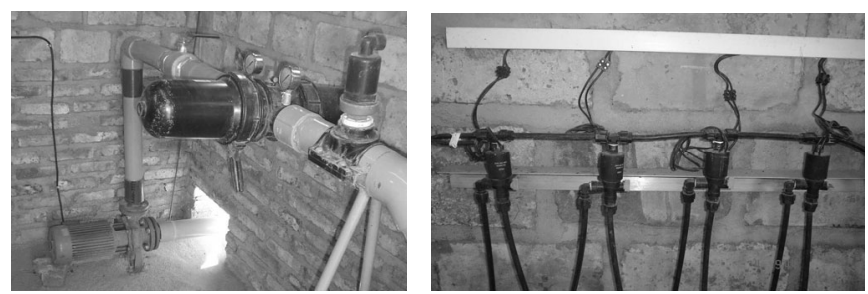

Fig 2: Irrigation head: Pump, filter and electric control valves

The electronic control system is composed by a personal computer (PC) and a control panel. The PC monitors the moisture level and runs the control algorithm for the valves in each AHP. The control panel contains the necessary electronics components for the operation of the irrigation system: power supply, relays, communication module, protection electric and others. The PC and all installed sensors are connected to a RS-485 serial network.

\subsection{Moisture sensor, field installation and adjustment.}

The moisture sensor used in this application was developed at the Instituto de Automática, UNSJ (patent pending). This sensor is based on the capacitive behavior of the soil; the value given by the sensor is a dimensionless measurement of the soil moisture (Hn). Sensors should be installed underground, within the roots zone (see Fig. 3), and then calibrated, in order to obtain a real value of volumetric soil moisture (Hv).
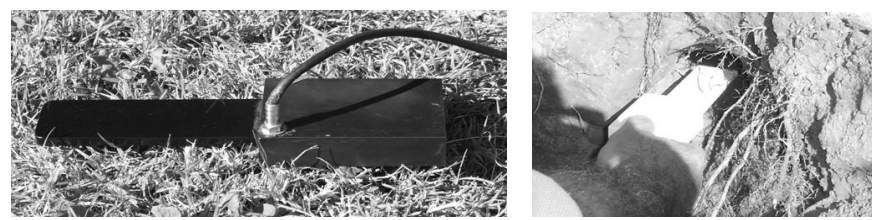

Fig 3: Moisture sensor and rootzone installations.

Given a linear relationship between $\mathrm{Hn}$ and Hv (Vita Serman et al. 2005), the calibration curve of the moisture sensors will be a straight line (1). In order to obtain the parameters $m$ and $b$ of the line, (2) and (3), two measurements of the soil are necessary in different moisture conditions. Measurements must be done simultaneously by the sensor (Hn) and by taking a sample of the soil close to the sensor and then analyzing the sample in the laboratory (Hv). From these tests, two measurements from the sensor ( $\mathrm{Hn} 1$ and $\mathrm{Hn} 2$ ) and two laboratory measurement (Hv1 and Hv2) are given.

$$
\begin{gathered}
H v=m \cdot H n+b \\
m=\frac{H v_{2}-H v_{1}}{H n_{2}-H n_{1}} \\
b=\frac{H v_{2} \cdot H n_{1}-H v_{1} \cdot H n_{2}}{H n_{1}-H n_{2}}
\end{gathered}
$$

The larger is the difference between measurements, the more accurate is the sensor calibration. In this sense it is convenient that one of these measurements is taken when the moisture level is close to field capacity while the second is close to a plant water stress. These intervals can be determined by measuring the leaf water potential with a pressure chamber (Scholander et al., 1965). Determination of some points within these intervals is also convenient, but not always possible, due to time and economic reasons. In this case, necessary measurements for calibrating the moisture sensors were taken in AHP A and B, as parcels C and D had similar composition and textures as parcel A. Table 1 summarizes the results obtained.

Table 1: Calibration parameters

\begin{tabular}{|c|c|c|c|c|}
\hline \multirow{2}{*}{$\mathbf{A H P}$} & $\boldsymbol{H n}$ & $\boldsymbol{H} \boldsymbol{v}$ & $\boldsymbol{m}$ & $\boldsymbol{b}$ \\
\hline \multirow{2}{*}{$\mathrm{A}$} & 20,37 & 23,22 & \multirow{2}{*}{1,72} & $-11,81$ \\
\cline { 2 - 3 } & 27,43 & 35,36 & & \\
\hline \multirow{2}{*}{$\mathrm{B}$} & 24,31 & 13,85 & \multirow{2}{*}{2,38} & -44 \\
\cline { 2 - 3 } & 29,12 & 25,30 & & \\
\hline
\end{tabular}

\section{CONTROL ALGORITHM}

The control algorithm should be able to maintain the soil moisture around the reference Hr. The proposed algorithm consists of a mathematical model of the dynamic water state of the soil together with identification and prediction strategies; this controllers are a new research field. Figure 4 shows a schematic of the complete system.

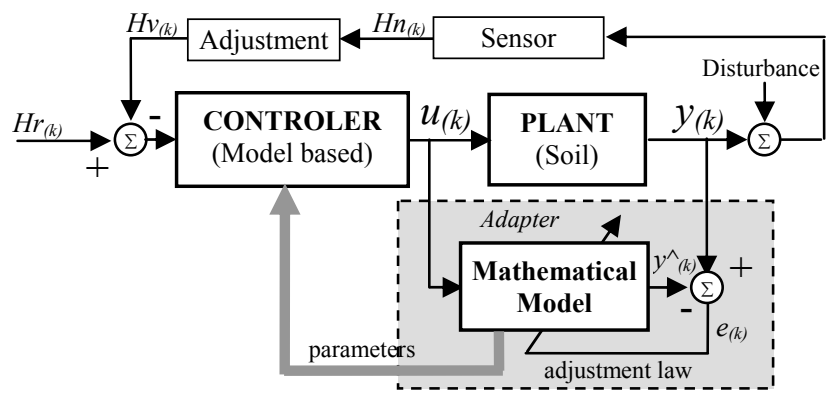

Fig. 4: System block diagram

The controller calculates, every sample time $(\mathrm{To}=15 \mathrm{~min})$, the frequency and length of irrigation for each AHP, in order to reach and maintain the desired moisture level and minimize variations. This calculation is based on current measurements 
from the roots zone moisture of the crop and on the prediction of the system future behavior. The model used for prediction is automatically on-line updated according to variations of the soil.

\subsection{Dynamical model of the soil.}

The mathematical model used to represent the water dynamics of the soil is a simple input - simple output (SISO) system (presented in Fig. 5). This is a simplified model which requires the measurement of only one field variable, in this case Hn. The input applied to the model is the irrigation caudal supplied to the crop and the output is the moisture present in the measurement zone (the effect of consumption water crop, global radiation and rain are considerate as disturbances).

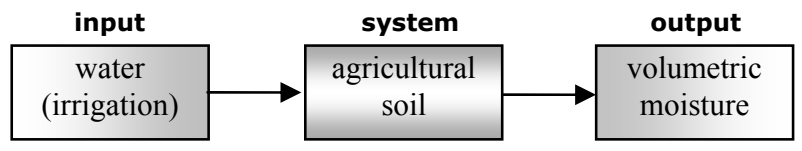

Fig. 5: System description (open-loop).

After defining the model structure, an off-line identification process is accomplished, using data gathered from several open-loop experiments in the field. The identified model allows simulating the dynamic behavior of different kind of soils, relating the irrigation caudal and the moisture level.

\subsection{Software}

The control algorithm was implemented in $\mathrm{C}++$, and runs in a PC, installed inside the control room. The software has two main functions. The first one is the controller itself, which takes decisions about how to manage the irrigation valves. The second corresponds to a monitoring function that allows to the user to visualize moisture levels, set the controller parameters, define characteristics for each AHP, save data and operate the system in a manual mode. The developed software operates as follow:

1.- The software read the values from each sensor, and presents this information on the operator screen.

2.- The algorithm determines the irrigation sequence in function of the water requirements of each AHP, giving higher priorities to those AHP where the difference between the $\mathrm{Hr}$ and the sensor's values was greater. Furthermore, the algorithm analyzes the water serving capacity: depending on the design of the system, sometimes is not possible to attend more than one or two zones simultaneously. In general, the hydraulic design is done with the capacity of attending at least one zone at once. This means that the pump caudal should be greater than the necessary caudal for satisfying the largest AHP (in this particular case is AHP C).

3.- The next step is to calculate the irrigation length for each AHP. To do this, a prediction of the future behavior of the system is performed, by using the identified mathematical model of the soil.

4.- After determining the irrigation intervals, the control action is released to each irrigation control valve. In the next sample time, the algorithm evaluates the error between the actual moisture level reached by the soil and the value calculated by the predictor; if this error is out of the allowed tolerances $(+/-0.4 \%)$, then the identification algorithm must recalculate the parameters of the model.

\subsection{Simulations.}

In order to understand the dynamics of the soil irrigation model and compare results with those from the intelligent irrigation controller, the timed irrigation technique was used in first simulation. A loamy soil was supposed for the simulations. As initial conditions, a completely dry soil was simulated and the moisture set point was $\mathrm{Hr}=30 \%$. A disturbance (strong rain) is introduced in the experiments.

In Fig. 6 timed irrigation was performed with a cycle of $6 \mathrm{~h}$ of irrigation every $72 \mathrm{~h}$. From this simulation some important conclusions can be obtained. The timed irrigation control is not able to manage disturbances, due to the fact that this is an open-loop method and takes too much time to reach the moisture set point. It is worth to note that the higher is the irrigation frequency, the less are the variations on the moisture level respect to $\mathrm{Hr}$.

Once the soil's dynamic behavior has been understood, a simulation of the proposed intelligent irrigation controller is performed; Fig. 7 shows the new result obtained. The fast controller response results in a short settle time and in presence of disturbances the control sequence is modified, as shown in the same figure. Variations on the moisture level respect to the set point are minimized by using short irrigation intervals. This modern irrigation control technique is known as high frequency local irrigation and has the advantage of reducing water consumption (Pizzarro, 1996).

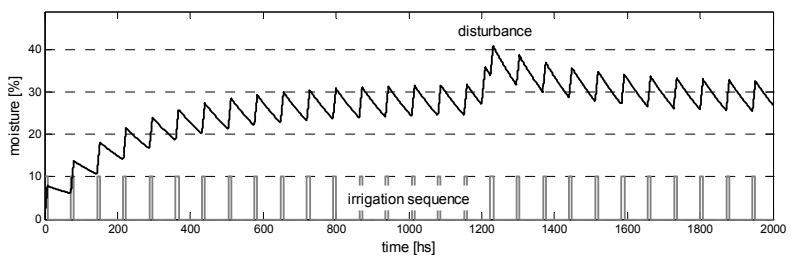

Fig. 6: Soil response using timed irrigation.

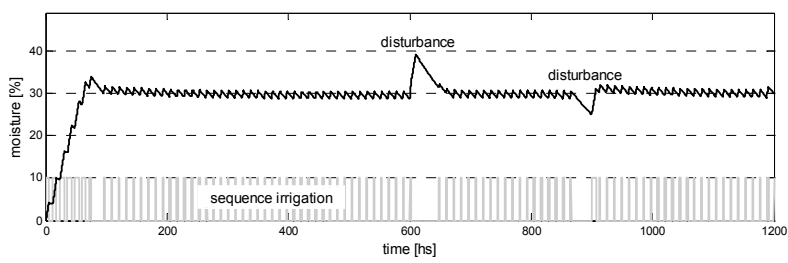

Fig. 7: Soil response using intelligent irrigation control.

\section{FIELD IMPLEMENTATION AND RESULTS.}

Results obtained from the field implementation are presented; shown data correspond to moisture variation in each AHP. Each AHP is analyzed separately. Discontinuities in the figures are due to some missing data caused by main power cuts in the area. 
Remember that relevant areas are AHP A and C; although these AHPs have the same characteristics, they will be controlled under different irrigation patterns in order to evaluate the wine quality made from grapes from these zones. These irrigation patterns will be characterized by Twr ( $\mathrm{Hr}$ $=25 \%)$ for the parcel $\mathrm{A}$ and $\operatorname{Tr}(\mathrm{Hr}=30 \%)$ for parcel $\mathrm{C}$.

For the AHP A, the moisture reference value is initially $\mathrm{Hr}=$ $35 \%$; once this value is reached and stabilized, the $\mathrm{Hr}$ is reduced to the restriction water deficit level $(25 \%)$. Figure 8 shows that in this case, the controller decides not to irrigate until the moisture level falls below the reference. After that, on January $25^{\text {th }}$, a severe disturbance, caused by a broken valve, appears. This condition was used to check the behavior of the controller when facing disturbances; the controller realizes this situation and alters irrigation cycles.

In the case of the AHP B, a $\mathrm{Hr}=26 \%$ is set along all the experiment (see Fig. 9). Another kind of perturbation was evaluated on this area: the lack of water (lack of water in the reservoirs, obstruction of the pump or pipes, burst of the pipes, main power cuts, etc). In this case, the controller has promptly responded as soon as the problem is fixed. Due to that this area has sandy soil it can be observed that moisture falls faster when there is water lack.

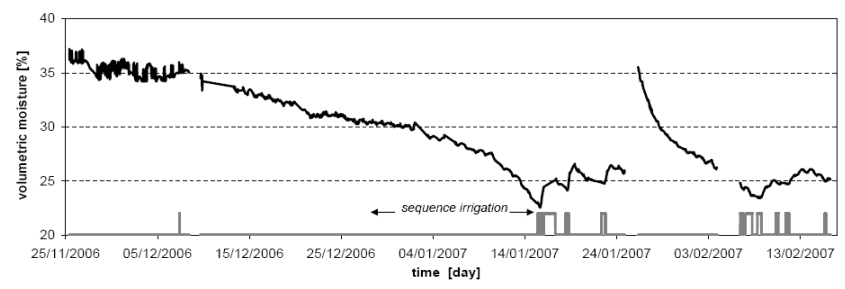

Fig. 8- Moisture variation, AHP “A”.

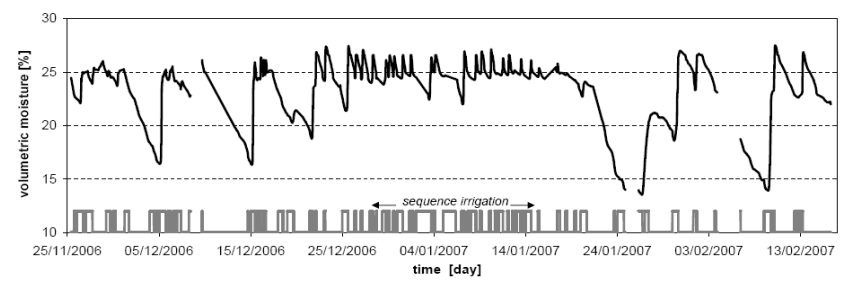

Fig. 9- Moisture variation, AHP “B”.

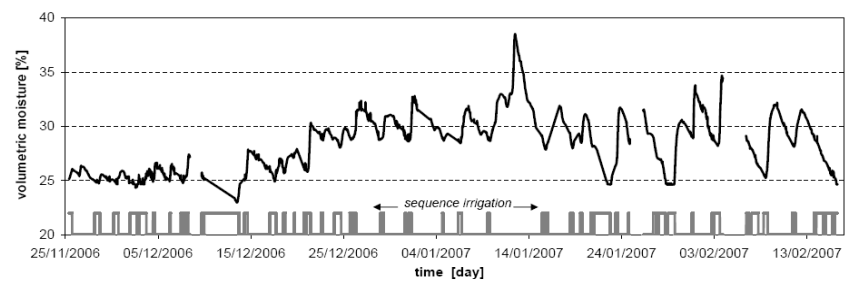

Fig. 10- Moisture variation, AHP “C”.

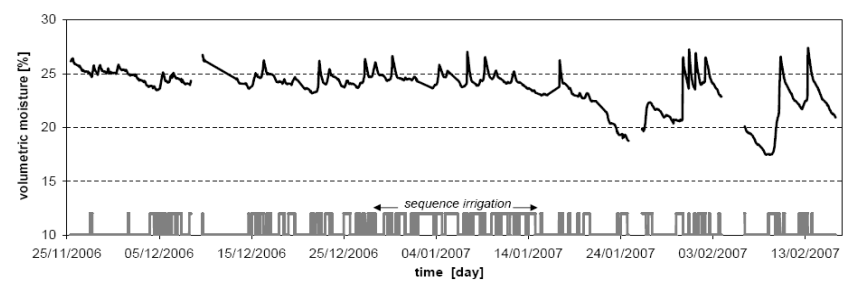

Fig. 11- Moisture variation, AHP “D”.
AHP C initially has an $\mathrm{Hr}=26 \%$ that is subsequently augmented to $30 \%$. Results presented in Fig. 10 show that this area had the largest moisture variations when reference was set to $30 \%$. This was caused by the fact that this is the largest parcel and consequently has more water requirements and takes almost the whole installed water caudal. When other areas have priority, the controller decides to stop irrigating this parcel. A solution to this problem would be to alter the priority schema, giving higher values to parcel $\mathrm{C}$, or increase the installed water caudal, as it was mentioned.

In parcel $\mathrm{D}, \mathrm{Hr}=25 \%$ is maintained along the whole experiment. Figure 11 shows the temporal evolution of the moisture in this area. In this parcel, the experiment consisted on checking the controller's behavior as regulator, without adding perturbations. However, by mistake, an operator disabled the control system between the 20th and the 25 th January and the same happened between the 3rd and the 9th February. This means that within these days, the controller did not operate on the valves. In spite of this mistake, the controller performed well and was able to promptly reach and maintain the moisture reference.

\section{GRAPE PRODUCTION AND WINE CHARACTERISTICS}

The evaluation of enological and organoleptic wine characteristics was made for the two irrigation treatments. The enological process used $100 \mathrm{~kg}$ of grapes from sectors A and C. After an initial analysis, the comparison of the results obtained from the grapes from $\mathrm{A}$ and $\mathrm{C}$ are summarized in Table 2 .

Table 2. Análisis iniciales de uvas $c v$. Malbec

\begin{tabular}{|c|c|c|c|}
\hline Treatments & ${ }^{\mathbf{o}}$ Brix & Total Acidity & pH \\
\hline Tt & 25,40 & 6,07 & 3,96 \\
\hline Twr & 26,50 & 6,02 & 3,93 \\
\hline
\end{tabular}

\subsection{Sensorial analysis.}

After preprocessing the grapes, and following exactly the same procedure, two different wines were obtained. The chemical analysis of these wines are presented in Tables 3, 4 and 5 .

Table 3. Final analysis of cv. Malbec grapes

\begin{tabular}{|c|c|c|c|c|}
\hline Treatments & $\begin{array}{c}\text { Alcohol \% } \\
\mathbf{v} / \mathbf{v}\end{array}$ & $\begin{array}{c}\text { Total Acidity } \\
\left(\mathbf{g L}^{-1}\right)\end{array}$ & $\mathbf{p H}$ & $\begin{array}{c}\text { Reducing sugar } \\
\left(\mathbf{g L}^{-1}\right)\end{array}$ \\
\hline Tt & 14.79 & 5.71 & 4.16 & 6.56 \\
\hline Twr & 15.23 & 6.25 & 4.15 & 6.60 \\
\hline
\end{tabular}

Table 4. Analysis of polyphenolic characteristics

\begin{tabular}{|c|c|c|c|c|c|}
\hline $\begin{array}{c}\text { Treat } \\
\text { ments }\end{array}$ & $\begin{array}{c}\text { Total } \\
\text { anthocians }\end{array}$ & $\begin{array}{c}\text { Flava } \\
\text { noles }\end{array}$ & Tanines & $\begin{array}{c}\text { IPT } \\
\text { (D.o. 280) }\end{array}$ & $\begin{array}{c}\text { IC (420+ } \\
\text { 520+620) }\end{array}$ \\
\hline Tt & 323.11 & 367.31 & 820.31 & 55.60 & 1.01 \\
\hline Twr & 437.56 & 470.34 & 1023.39 & 76.30 & 1.47 \\
\hline
\end{tabular}

The Table 4 shows important differences between both treatments. The Twr reach a major chemical quality for the phenolic analysis. 


\subsection{Descriptive analysis.}

The organoleptic analysis was performed with a panel of seven expert referees, by a descriptive analysis and preference tests, always working on unidentified samples. In the case of the descriptive analysis, descriptors used to differentiate the wines are set first. Next, the intensity of each descriptor is quantized within a range between 0 and 5 . The average of the seven referee's results is presented in Fig. 12. Similarly, the preference of the board of referees was determined by a rank test (Kramer test), which determined that, from seven referees, five of them chose the wine obtained by applying the Twr treatment as more preferred.

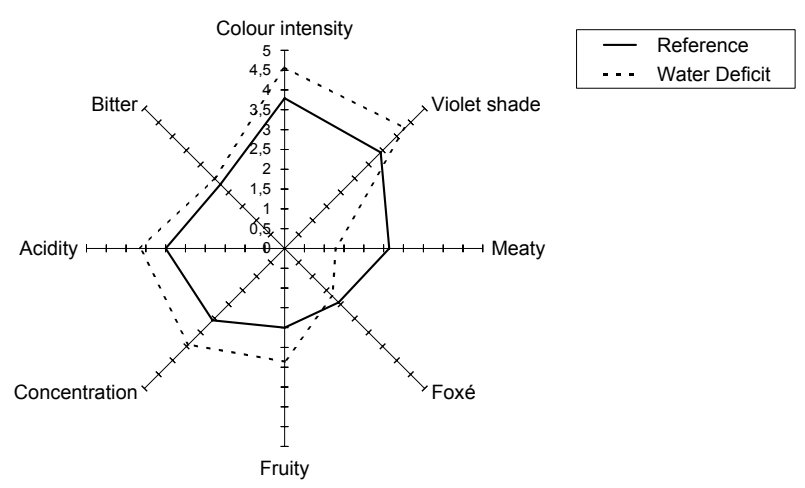

Fig 12- Values for the organoleptic descriptors.

\section{CONCLUSIONS}

The proposed controller performed well and control objectives were satisfactorily achieved. In addition this controller presents substantial advantages over timed controllers. The proposed approach allows reaching desired moisture values in the root zone by successive predictions, involving the mathematical model of the soil and using only the strictly necessary amount of water. In this way different enological quality grapes can be obtained and hence different kind of wines can be produced.

The presented structure allows also the parameters adjustment in the identified model when changes on the physical characteristics of the soil take place; in this sense, continuous measurement of parameters and model adjustments result in an improved behavior of the controller over time. At the same time, the controller is able to deal with perturbations by adjusting fast and automatically the irrigation strategies.

The intelligent irrigation control system uses only the strictly necessary amount of water to maintain the soil moisture around the desired values, avoiding lixiviation and run off losses as well as phreatic and salinity problems, associated to the misuse of water. In arid or semiarid areas, such as San Juan, Argentina, where agriculture depends exclusively on irrigation and water resources are poor, the efficient use of water has an important economical and environmental effect.

Finally, as was presented in the enological results of Section 6 , there was a significant difference between the results obtained for the grapes of each treatment. With respect to the wine obtained from the grapes with water stress treatment, the conclusion of the referee's board was that this wine is some more preferable that the reference one.

\section{REFERENCES}

Bravdo B, Hepner Y, Loinger C, Cohen S, Tabacman H. (1985). Effect of irrigation and crop level on growth, yield and wine quality of Cabernet Sauvignon. American Journal of Enology and Viticulture 36: 132-39.

Capraro F, C. Schugurensky, F. Vita, S. Tosetti, A. Lage, J. Pucheta (2007). Intelligent irrigation control in agricultural soils: an application to grapevines. XII RPIC. Rio Gallegos. Argentina

Capraro F, D. Patiño, C. Schugurensky, R. Sullana, S. Tosetti (2006). Diseño de un controlador de humedad en suelos agrícolas empleando redes neuronales. $X X$ AADECA '06, Buenos Aires, ARGENTINA.

Coggan M. (2002). Water measurement in soil and vines. Vineyard \& Winery Magazine, 28(3): 43-53

Dry P.R. and B.R. Loveys, (1998). Factors influencing grapevine vigour and the potential for control with partial rootzone drying. Australian Journal of Grape and Wine Research 4 (3): 140-148.

Dry P.R., B.R. Loveys, M.G. Mccarthy, and M. Stoll. (2001). Strategic irrigation management in Australian vineyards. Jour. Int. des Sciences de la Vingen et du Vin 35: 129139.

Goodwin, I., and I. Macrae. (1990). Regulated déficit irrigation of Cabernet Sauvignon grapevines. Australian and New Zealand Wine Industry Journal 5: 131-133.

López, Hernández, Pérez and González (1997). Riego localizado, II edición, Ed. Mundi-Prensa, España

McCarthy, M.G (1997). The effect of transient water deficit on berry development of cv. Shiraz (Vitis vinifera L.). Austral. J. Grapewine Res. 3: 102-108.

Nadal, M., and L. Arola (1995). Effects of limited irrigation on the composition of must and wine of Cabernet Sauvignon under semi-arid conditions. Vitis 34:151-154.

Peterlunger E, Buccella A, Iacomo F, Bradvo BA (2000). Physiological change in grapevine during adjustment to water stress: ABA, leaf gas exchanges and root hydraulic conductivity. Acta Horticulturae 526: 201-208

Pizarro F. (1996) Riegos localizados de alta frecuencia, III Edición, Ed. Mundi-Presa, España

Scholander, P.F., H.T. Hammel, E.D. Bradstreet y E.A. Hemmingson. (1965). Sap pressure in vascular plants. Science 148: 339-346.

Vita Serman F., C. Schugurensky, R. Carrión y S. Rodríguez. (2005). Evaluación del comportamiento de sensores de humedad de suelo de desarrollo local, en relación al contenido de agua y a la textura de suelo, CONAGUA 2005. Mendoza, Argentina 